\title{
Free Radical Scavenging Activity of the Medicinal Malaysian Leech Saliva Extract, Hirudinaria manillensis
}

\author{
Abbas Mohammad Ghawi ${ }^{1 *}$, Abdualrahman M. Abdualkader ${ }^{2}$, Ahmed Merzouk ${ }^{3}$ and Mohamed Alaama ${ }^{2}$ \\ ${ }^{1}$ Basic Medical Science Department, Faculty of Pharmacy, International Islamic University, Malaysia, Kuantan, Pahang, Malaysia \\ ${ }^{2}$ Pharmaceutical Chemistry Department, Faculty of Pharmacy, International Islamic University Malaysia, Kuantan, Pahang, Malaysia \\ ${ }^{3}$ Biopep Solutions Inc., Vancouver, BC, Canada
}

\begin{abstract}
Antioxidants from natural sources have been arisen as prophylactic and therapeutical agents in many lifethreatening disorders such as cancer and cardiovascular diseases. Leech therapy has been used since the extreme old ages in a variety of abnormalities. The current study was executed to examine the antioxidant activity of the salivary gland secretion of the medicinal Malaysian leech using DPPH free radical scavenging activity method. Leech saliva extract (LSE) was collected from starved leeches after feeding them on the phagostimulatory solution of $0.001 \mathrm{M}$ arginine in $0.15 \mathrm{M}$ sodium chloride. Total protein concentration was $78.753 \pm 2.406 \mu \mathrm{g} / \mathrm{ml}$. A series of different dilutions of LSE were mixed with DPPH in a methanolic medium and the changes in absorbance were measured at $516 \mathrm{~nm}$. Results showed that LSE expressed a free radical scavenging activity with $I C_{50}$ of $7.282 \mu \mathrm{g} / \mathrm{ml}$ compared with $5.803 \mu \mathrm{g} / \mathrm{ml}$ of L-ascorbic acid as a positive control. Therefore, this study revealed that the proteomic contents of LSE are promising natural antioxidants.
\end{abstract}

Keywords: Antioxidants; DPPH; Free radical; leech; leech saliva Introduction

Recently, it was discovered that free radicals-mediated oxidative stress can seriously influence the structure and function of tissues, cells and their components involving DNA, enzymes, lipids and carbohydrates. Consequently, these effects lead to irregular biological events such as lipid peroxidation byproducts, DNA fragmentation and even accelerated cell death. The progressive accumulation of these products will result in various diseases: cardiovascular diseases, cancer, neuropathy disorders, and so forth $[1,2]$.

Antioxidant is a substance capable of frustrating or restricting the oxidation of other oxidizable molecules by suppressing the free radicalcaused oxidation chain reaction. Antioxidants exhibit their activities by being involved in the oxidation process themselves rather than the biological targets [3].

On the other hand, antioxidants have gained a remarkable interest by scientists because of their valuable potential application in medicine and industry. They have very promising applications as prophylactic and therapeutical agents for many life-threatening illnesses [4]. Some reports suggested that people who routinely intake flavonoid from tea, fruits and vegetables are at lower risk of developing coronary heart diseases and stroke [5]. Hence, the affectivity of antioxidants in diseases preventing and treatment is still controversial [1].

As far as we know, there is lack of documented data about the antioxidant activity of leech salivary gland secretion or any usage of leech therapy as antioxidant agent. Thus, we aimed from the current study to evaluate the free radical scavenging activity of the proteomic contents of the salivary gland secretion of the medicinal Malaysian leech, Hirudinaria manillensis.

\section{Materials and Methods}

\section{Chemicals, Reagents and instrumentation}

Methanol (MEOH) was the product of Fischer Scientific (USA). L-Ascorbic acid was purchased from Calbiochem (Canada). Arginine hydrochloride, bovine serum albumin (BSA) and DPPH (2,2-Diphenyl1-picrylhydrazyl) was obtained from Sigma Aldrich (Germany). Sodium chloride $(\mathrm{NaCl})$ was from Merck (Germany). Bradford reagent kit was obtained from Amresco (USA).

Infinite M200, NanoQuant TECAN multi detection microplate reader was the product of TECAN (USA). Centrifugation was carried out using centrifuge Hettich Zen Trifugen Universal 32R (Germany). Lyophilization was performed using Christ freeze-drier model Alpha 1-4LD (Germany).

\section{Leech sampling and saliva collection}

Leeches, Hirudinaria manillensis, were collected from the natural lake, Cheneh, located in Trengganu, Malaysia. They were maintained in well-aerated plastic containers filled with un-chlorinated tap water. Water was regularly changed every two days. The collected leeches were kept in a room under $12 \mathrm{~h}: 12 \mathrm{~h}$ light and dark cycle at the room temperature $\left(25 \pm 1^{\circ} \mathrm{C}\right)$.

Leech saliva extract (LSE) was collected as previously described [6]. Starved leeches were fed on the phagostimulatory solution (PHS) of $0.001 \mathrm{M}$ arginine in $0.15 \mathrm{M}$ sodium chloride through parafilm membrane. Only the colorless salivary fluids vomited by the 69 leeches were pooled and centrifuged at $+4^{\circ} \mathrm{C}$ and at $2500 \mathrm{rpm}$ for 10 min [7] and the 70 supernatant was filtered using $0.45 \mu \mathrm{m}$ Sartorius ${ }^{\mathbb{R}}$ filter paper. The resultant LSE was aliqouted in 1-ml galss tubes and

*Corresponding author: Abbas Mohammad Ghawi, Basic Medical Science Department, Faculty of Pharmacy, International Islamic University Malaysia, Jalan Istana, 25200 Kuantan, Pahang, Malaysia, E-mail: azawiabbas@yahoo.com

Received April 04, 2012; Accepted April 26, 2012; Published April 28, 2012

Citation: Ghawi AM, Abdualkader AM, Merzouk A, Alaama M (2012) Free Radical Scavenging Activity of the Medicinal Malaysian Leech Saliva Extract, Hirudinaria manillensis. J Bioequiv Availab S14. doi:10.4172/jbb.S14-001

Copyright: (C) 2012 Ghawi AM, et al. This is an open-access article distributed under the terms of the Creative Commons Attribution License, which permits unrestricted use, distribution, and reproduction in any medium, provided the original author and source are credited. 
Citation: Ghawi AM, Abdualkader AM, Merzouk A, Alaama M (2012) Free Radical Scavenging Activity of the Medicinal Malaysian Leech Saliva Extract, Hirudinaria manillensis. J Bioequiv Availab S14. doi:10.4172/jbb.S14-001

lyophilized for $24 \mathrm{~h}$. The resultant lyophilized LSE was used during the experimental procedures.

\section{Total protein estimation}

Total protein concentration assay was executed as described by Bradford (1976) and the standard protocols of Bradford reagent kit [8] using BSA as a standard protein and the PHS as a blank.

\section{Free radical scavenging activity}

Antioxidant activity was measured by the method of Blois (1958) in terms of radical scavenging ability using DPPH method in a methanolic medium [9-11].

The lyophilized LSE was dissolved in MEOH yielding a 3-time concentrated LSE, and the resultant methanolic solution was termed as $3 \times \mathrm{mLSE}$. Volumes of $100 \mu \mathrm{l}$ of serial double-fold dilutions of the $3 \times$ mLSE were pipetted into $96-$ well plate. Then, all volumes were brought to a final volume of $300 \mu \mathrm{l}$ by $\mathrm{MEOH}$. Then, $15 \mu \mathrm{l}$ of methanolic DPPH solution $84(0.002 \mathrm{M})$ was added and the $\mathrm{A}_{516}$ were taken after $15 \mathrm{~min}$. the same procedure were performed using serial step-wise dilutions of L-ascorbic acid $(50 \mu \mathrm{g} / \mathrm{ml})$ in methanol as a positive control. The PHS was used as a negative control. Finally, a volume of $15 \mu \mathrm{l}$ of DPPH was added to $300 \mu \mathrm{l}$ of $\mathrm{MEOH}$ and $\mathrm{A}_{516}$ was measured immediately as a control reading. The free radical scavenging activity (\%antiradical activity) was estimated from the equation:

\section{$\%$ antiradical activity $=$ \\ Control absorbance - Sample absorbance Control absorbance $\times 100$}

All measurements were repeated in triplicates, and the mean \pm standard error of the mean (SEM) was considered. The concentration of ascorbic acid and the LSE proteins $(\mu \mathrm{g} / \mathrm{ml})$ that required for scavenging $50 \%$ of DPPH $\left(\mathrm{IC}_{50}\right)$ was estimated from the curve resulted from plotting $\%$ antiradical activity against the concentrations $(\mu \mathrm{g} / \mathrm{ml})$. Plots were carried out using Four Parametric Logistic Equation using Sigma Plot 11.0 software.

\section{Results}

\section{LSE collection and total protein estimation}

The total volume of LSE collected from the starved leeches was $20 \mathrm{ml}$. Bradford assay (Figure 1) revealed that the collected LSE contained a total protein concentration of $78.753 \pm 2.406 \mu \mathrm{g} / \mathrm{ml}$. Consequently, the total protein concentration of the extract used during the experiment, $3 \times \mathrm{LSE}$, was $236.259 \mu \mathrm{g} / \mathrm{ml}$.

\section{Free radical scavenging activity}

Results (Figure 2a and $2 \mathrm{~b}$ ) showed a dose dependent free radical scavenging activity of LSE with IC $_{50}$ of $7.282 \mu \mathrm{g} / \mathrm{ml}$. Similarly, L-ascorbic acid was found to be a free radical scavenger with $\mathrm{IC}_{50}$ of $5.803 \mu \mathrm{g} / \mathrm{ml}$.

\section{Discussion}

Results presented in this study illustrated that LSE from the medicinal Malaysian leech had a free radical scavenging activity in a dose dependent manner. According to our knowledge, we are the first who enlightened the antioxidant activity of leech salivary gland secretion. The antioxidant activity of LSE can be explained based on the definition of DPPH free radicals and the methods by which these free radicals could be scavenged.

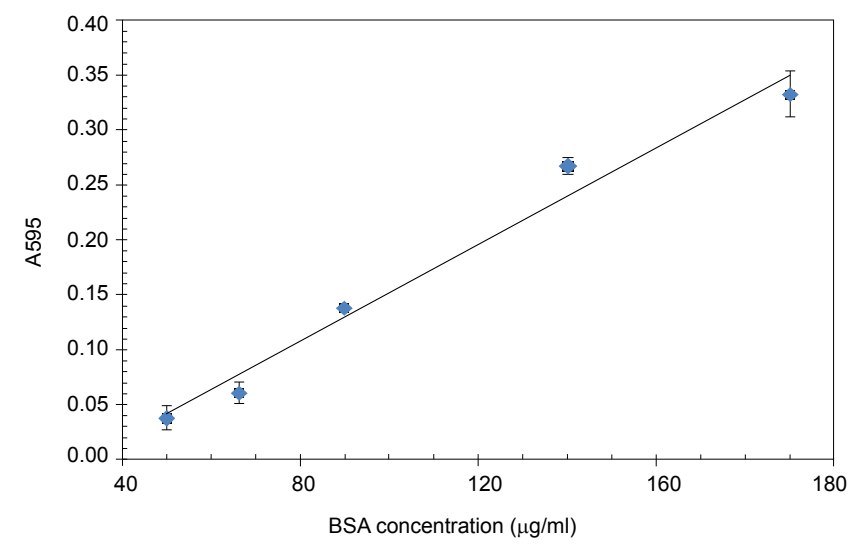

Figure 1: The standard curve for total protein estimation of LSE performed according to Bradford assay. All results are the mean of triplicates \pm standard deviation (SD). $Y=0.002 X+0.020$, where: $X=B S A$ concentration $(\mu \mathrm{g} / \mathrm{ml})$ and $Y=$ absorbance at $595 \mathrm{~nm}, \mathrm{R}^{2}=0.981$.
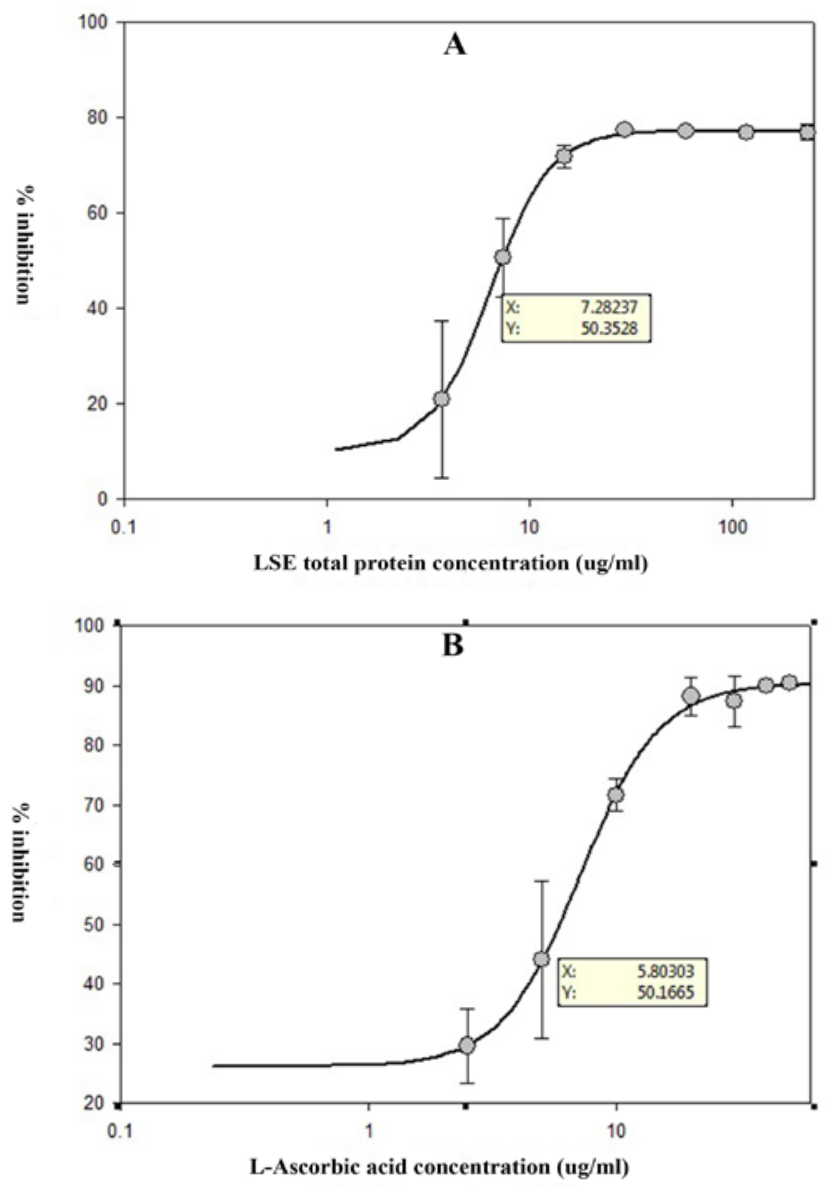

Figure 2: Dose responsive curve of DPPH free radical scavenging activity of LSE (A) and L-ascorbic acid (B). All measurements were repeated in triplicates, and the mean \pm standard error of the mean (SEM) was considered.

Generally speaking, oxidation reaction series includes three steps: induction, propagation and termination [12]. These progressive complex reactions terminate when two free radicals react with each other forming more stable non-radical products. On the other hand, 
hydrogen donor molecules $(\mathrm{AH})$ can stop oxidation when hydrogen atom $\left(\mathrm{H}^{*}\right)$ binds the reactive free radicals. On the other hand, antioxidants are chemical compounds which have the capability of stopping the oxidation events by acting at different levels of the three-step chains. They can restrain the generation of free radicals. In addition, they can block propagation by many proposed mechanisms including scavenging reactive species, breaking the chain reaction, etc. [13].

Likewise, the methanolic solution of DPPH can generate stable free radicals which can initiate redox reaction chains producing oxidation by-products [14]. In the presence of 123 antioxidants (AH), hydrogen atoms $\left(\mathrm{H}^{\circ}\right)$ would bleach the free radicals $\left(\mathrm{DPPH}{ }^{*}\right)$. Consequently, scavenging of free radical would result in interrupting both chain initiation and propagation $[12,14]$.

In our study, LSE exhibited a free radical scavenging activity. This activity could be ascribed to many suggested factors. First, it has been reported that the aromatic and phenolic rings play the role of $\left(\mathrm{H}^{\circ}\right)$ donor to the reactive free radicals. After hydrogen atom donation, these rings become also radicals which would be stabilized by resonance delocalization of the electron within the aromatic ring. Many phenolcontaining natural antioxidants, such as flavonoids, exhibit their activity in this manner [13]. Thus, we can suggest that the proteomic contents of LSE donate $\left(\mathrm{H}^{*}\right)$ via the phenolic and aromatic rings of the amino acids included in their structure. For example, Phe was found to be an important component in the structure of the tetra-peptidic antioxidant purified from the viscera protein of horse mackerel fish [15].

Second, the enzymatic formation of thiol groups (-SH) from disulfide bonds (-S-S-) is considered one of the cellular antioxidant mechanisms. The reaction between thiol groups and free radical produces thiyl radicals $\left(\mathrm{RS}^{\circ}\right)$ which will be stabilized by gaining $\left(\mathrm{H}^{*}\right)$ or by forming covalent adducts [16]. Thus, we can postulate that (-SH) groups in cysteine (Cys) rich proteins in LSE could play an important role as antioxidant. This assumption could be 140 supported by the previously proved importance of Cys in antioxidant peptides. This antioxidant ability of Cys was referred to its hydrophobicity which enables it to interact easily with free radicals as a proton donor [17], like the tetra-peptidic antioxidant (Ala-Cys-Phe-Leu) isolated from the viscera protein of horse mackerel fish [15].

Third, some amino acids (His, Pro, Cys, Tyr, Trp, Phe and Met) were reported as crucial elements to elucidate the antioxidant activity of peptides due to their hydrophobic properties. The existence of such amino acids enhances peptide solubility in lipid and proton donation $[17,18]$. For instance, three antioxidant peptides containing hydrophobic amino acids were isolated from water buffalo horn [19]. Our suggestion is the presence of such amino acids in the primary structure of the proteomic contents of LSE may responsible for the free radical scavenging activity of leech saliva.

To be considered, the extraordinary combination between the antithrombin activity of 152 LSE we have previously described [6] and the antioxidant activity of the medicinal Malaysian LSE makes it a promising medication in cardiovascular diseases (CVDs). It was already proved that the direct thrombin inhibitor, hirudin, extracted from the salivary gland 155 secretion of the medicinal leech $H$. medicinalis had prophylactic and therapeutical applications in various CVDs like heparin-induced thrombocytopenia, pulmonary embolism, etc. $[20,21]$. Furthermore, some physicians argued that antioxidants have potential protective 158 effects against developing cardiovascular events. For example, the oxidized LDL has 159 damaging effects on the endothelial cells which eventually lead to atherosclerosis. In addition, oxidized LDL antibodies were considered as a risk factor in myocardial infarction.

However, the natural antioxidants act as scavengers of the free radicals and preventing fatty acid oxidation [22].

\section{Conclusion}

The outcomes of the current research outlined that the salivary gland secretion from the medicinal Malaysian leech, H. manillensis, had a significant free radical scavenging activity making it a novel therapeutic and prophylactic tool in the treatment of various ailments. However, more extensive studies still are needed to unveil the active compounds.

\section{Acknowledgment}

Authors would gratefully thank Roy T. Sawyer and Fred O. P. Hechtel, Leeches Biopharm (UK) Ltd, for their highly appreciated assistance in leech taxonomy This research was supported by the grant (EDW B 10-0393) from ResearchManagement Center, International Islamic University Malaysia.

\section{References}

1. Ratnam DV, Ankola DD, Bhardwaj V, Sahana DK, Kumar MN (2006) Role of antioxidants in prophylaxis and therapy: A pharmaceutical perspective. J Control Release 113: 189-207.

2. Beckman KB, Ames BN (1998) The Free radical theory of aging matures Physiol Rev 78: 547-581.

3. Sies H (1997) Oxidative stress: Oxidants and antioxidants. Exp Physiol 82 291- 295.

4. Bjelakovic G, Nikolova D, Gluud LL, Simonetti RG, Gluud C (2007) Mortality in randomized trials of antioxidant supplements for primary and secondary prevention. JAMA 297: 842-857.

5. Keli SO, Hertog MG, Feskens EJ, Kromhout D (1996) Dietary flavonoids, antioxidant vitamins, and incidence of stroke: The Zutphen study. Arch Intern Med 156: 637-642

6. Abdualkader AM, Merzouk A, Ghawi AM, Alaama M (2011) Some Biologica Activities of Malaysian Leech Saliva Extract. IIUM Engineering Journal 12: 1-9.

7. Rigbi M, Levy H, Iraqi F, Teitelbaum M, Orevi M et al. (1987)The saliva of the medicinal leech Hirudo medicinalis--1. Biochemical characterization of the high molecular weight fraction. Comp Biochem Physiol B 87: 567-573.

8. Bradford MM (1976) A rapid and sensitive method for the quantitation of microgram quantities of protein utilizing the principle of protein-dye binding Anal Biochem 72: 248-254.

9. Sanja SD, Sheth NR, Dhaval P, Biraju P (2009) Characterization and evaluation of antioxidant activity of Portucla oleracea. International Journal of Pharmacy and Pharmaceutical Science 1: 74-83.

10. Althunibat OY, Hashim RB, Taher M, Daud JM, Ikeda MA, et al. (2009) In vitro antioxidant and antiproliferative activities of three Malaysian sea cucumber species. European Journal of Scientific Research 37: 376-387.

11. Blois MS (1958) Antioxidant determinations by the use of a stable free radical. Nature 181: 1199-1200.

12. Bondet V, Brand-Williams W, Berset C (1997) Kinetics and mechanisms of antioxidant activity using the DPPH free radical method. LWT - Food Science and Technology 30: 609-615.

13. Brewer MS (2011) Natural antioxidants: Sources, compounds, mechanisms of action, and potential applications. Comprehensive Reviews in Food Science and Food Safety 10: 221-247.

14. Haripyaree A, Guneshwor K, Damayanti M (2010) Evaluation of antioxidant properties of some wild edible fruit extracts by cell free assays. Electronic Journal of Environmental, Agriculture and Food Chemistry 9: 345-350. 
Citation: Ghawi AM, Abdualkader AM, Merzouk A, Alaama M (2012) Free Radical Scavenging Activity of the Medicinal Malaysian Leech Saliva Extract, Hirudinaria manillensis. J Bioequiv Availab S14. doi:10.4172/jbb.S14-001

15. Sampath Kumar NS, Nazeer RA, Jaiganesh R (2011) Purification and biochemical characterization of antioxidant peptide from horse mackerel (Magalaspis cordyla) viscera protein. Peptides 32: 1496-1501.

16. Letelier ME, Molina-Berríos A, Cortés-Troncoso J, Jara-Sandoval J, Holst M, et al. (2008) DPPH and oxygen free radicals as pro-oxidant of biomolecules. Toxicol In Vitro 22: 279-286.

17. Hernández-Ledesma B, Dávalos A, Bartolomé B, Amigo L (2005) Preparation of antioxidant enzymatic hydrolysates from $\alpha$-Lactalbumin and $\beta$-Lactoglobulin. Identification of active peptides by HPLC-MS/MS. J Agric Food Chem 53: 588593.

18. Mendis E, Rajapakse N, Byun HG, Kim SK (2005) Investigation of jumbo squid (Dosidicus gigas) skin gelatin peptides for their in vitro antioxidant effects. Life Sci 77: 2166-2178.
19. Liu R, Wang M, Duan JA, Guo JM, Tang YP (2010) Purification and identification of three novel antioxidant peptides from Cornu bubali (water buffalo horn) Peptides 31: 786-793.

20. Markwardt F (2002) Historical perspective of the development of thrombin inhibitors. Pathophysiol Haemost Thromb 3: 15-22.

21. Corral-Rodríguez MA, Macedo-Ribeiro S, Pereira PJ, Fuentes-Prior P (2010) Leech-derived thrombin inhibitors: From structures to mechanisms to clinical aspplications. J Med Chem 53: 3847-3861.

22. Hercberg S, Galan P, Preziosi P, Alfarez MJ, Vazquez C (1998) The potential role of antioxidant vitamins in preventing cardiovascular diseases and cancers. Nutrition 14: 513-520. 